\title{
Passive Sampling of SARS-CoV-2 for Wastewater Surveillance
}

Christelle Schang, Nicolas D. Crosbie, Monica Nolan, Rachael Poon, Miao Wang, Aaron Jex, Nijoy John, Louise Baker, Peter Scales, Jonathan Schmidt, Bruce R. Thorley, Kelly Hill, Arash Zamyadi, Chi-Wen Tseng, Rebekah Henry, Peter Kolotelo, Jeroen Langeveld, Remy Schilperoort, Baiqian Shi, Steve Einsiedel, Michael Thomas, James Black, Simon Wilson, and David T. McCarthy*

Cite This: Environ. Sci. Technol. 2021, 55, 10432-10441 Read Online ACCESS | LWll Metrics \& More | 回 Article Recommendations

S1 Supporting Information

ABSTRACT: The shedding of pathogens by infected humans enables the use of sewage monitoring to conduct wastewater-based epidemiology (WBE). Although most WBE studies use data from large sewage treatment plants, timely data from smaller catchments are needed for targeted public health action. Traditional sampling methods, like autosamplers or grab sampling, are not conducive to quick ad hoc deployments and high-resolution monitoring at these smaller scales. This study develops and validates a cheap and easily deployable passive sampler unit, made from readily available consumables, with relevance to the COVID-19 pandemic but with broader use for WBE. We provide the first evidence that passive samplers can be used to detect SARS-

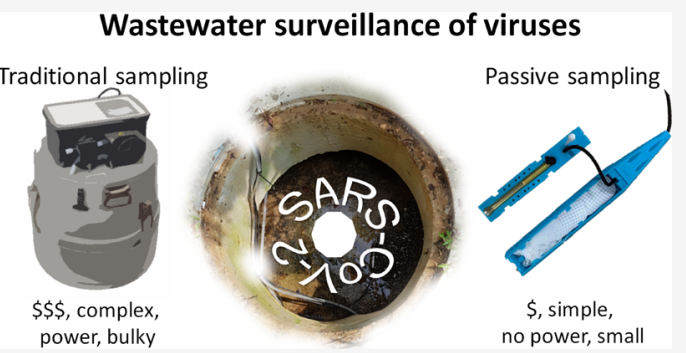
CoV-2 in wastewater from populations with low prevalence of active COVID-19 infections (0.034 to 0.34 per 10,000), demonstrating their ability for early detection of infections at three different scales (lot, suburb, and city). A side by side evaluation of passive samplers $(n=245)$ and traditionally collected wastewater samples $(n=183)$ verified that the passive samplers were sensitive at detecting SARS-CoV-2 in wastewater. On all 33 days where we directly compared traditional and passive sampling techniques, at least one passive sampler was positive when the average SARS-CoV-2 concentration in the wastewater equaled or exceeded the quantification limit of 1.8 gene copies per $\mathrm{mL}(n=7)$. Moreover, on 13 occasions where wastewater SARS-CoV-2 concentrations were less than 1.8 gene copies per $\mathrm{mL}$, one or more passive samplers were positive. Finally, there was a statistically significant $(p<0.001)$ positive relationship between the concentrations of SARS-CoV-2 in wastewater and the levels found on the passive samplers, indicating that with further evaluation, these devices could yield semi-quantitative results in the future. Passive samplers have the potential for wide use in WBE with attractive feasibility attributes of cost, ease of deployment at small-scale locations, and continuous sampling of the wastewater. Further research will focus on the optimization of laboratory methods including elution and extraction and continued parallel deployment and evaluations in a variety of settings to inform optimal use in wastewater surveillance.

KEYWORDS: wastewater surveillance, wastewater-based epidemiology (WBE), pathogens, water, sampling methods, surveillance, COVID-19, SARS-CoV-2, coronavirus

\section{INTRODUCTION}

Viral pathogens or their fragments can be excreted in the feces of infected individuals for weeks and sometimes years after the onset of infection. ${ }^{1,2}$ Viruses can also be shed by humans via respiratory and other bodily secretions, be in bathing, showering, and hand-washing waters or in surface cleaning matrices (e.g., of household floors and sinks). ${ }^{3}$ As such, sewer systems collect pathogen inputs over a wide area, facilitating wastewater-based epidemiology (WBE), ${ }^{4-7}$ the process of detecting pathogens of concern in wastewater streams and the subsequent inference about the health of the contributing population. $^{8-11}$

SARS-CoV-2, the virus responsible for the current COVID19 pandemic, is detectable in respiratory secretions as well as in the feces of infected humans. Viral fragments have been found in the stool of both asymptomatic and symptomatic persons infected with SARS-CoV-2 for 6 weeks or more from the time of infection with high intra- and inter-individual variability, spanning the early infectious and later noninfectious periods. ${ }^{12,13}$ These characteristics make WBE a promising additional environmental surveillance tool for early detection to complement individual clinical testing and to inform the response to the current COVID-19 pandemic.

Most studies that use WBE for pathogens undertake sampling at the intakes to sewage treatment plants (STPs),

Received: March 9, 2021

Revised: June 30, 2021

Accepted: July 1, 2021

Published: July 15, 2021

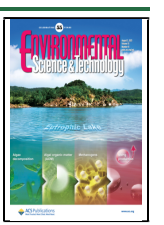


providing very useful city-scale, town-scale, or suburban scale information about infected populations both retrospectively ${ }^{14}$ and as an early warning tool to identify infections and take action before clinical cases manifest. ${ }^{10}$ However, monitoring at large STPs cannot provide timely information at the scale needed for targeted public health actions. This is especially the case for STPs in large cities, such as Melbourne, Australia, where two STPs treat wastewater from $\sim 3.7$ million people.

WBE at smaller scales, such as lot or suburb, can be achieved by monitoring within the wastewater network, including at pumping stations and from sewer manholes. This allows for a disaggregation of the catchment into specific smaller geographically defined sub-catchments, appropriately sized for targeted action and traceback. Such monitoring may also be used at smaller upstream locations including at specific facilities considered "at risk" for rapid transmission and/or high morbidity or mortality (e.g., aged care facilities). Further opportunities exist at correctional facilities, industry sites (abattoirs and distribution centers), schools, university campuses, and hotel quarantine locations. ${ }^{15}$

Although the application of WBE at smaller scales is appealing, collection of representative samples within the sewerage network presents several challenges. The collection of spot or grab samples is an option, but the high temporal variability of wastewater flows and pollutant concentrations at these smaller scales ${ }^{16,17}$ suggest that single grab sampling may reduce sensitivity and miss important information, such as shedding events. ${ }^{18}$ Ideally, multiple grab samples could be collected from each site, but this significantly increases costs and safety risks. To account for the dynamics of wastewater at these smaller scales, monitoring stations could be established with autosamplers and flow meters programmed to take frequent flow-proportional or time-proportional samples. ${ }^{18}$ Apart from requiring specialized skillsets, such installations are difficult at this scale because of (1) installation and maintenance costs, (2) equipment availability, (3) limited space and access to the sampling site, (4) safety concerns, especially as traffic management is commonly required, (5) the absence of a reliable power supply for refrigerated samplers, and (6) excessive sampling depths, which may be more than 10 $\mathrm{m}$ and is beyond the capacity of most autosampler pumps. As such, the widespread application of WBE to smaller scales requires alternative sampling approaches.

Passive sampling presents a cheap, safe, and easy alternative to traditional wastewater sampling within the sewage catchment for WBE. Passive sampling involves the deployment of a device in a waterbody for a known time period, allowing for pollutants in water to interact with the device. ${ }^{19-21}$ This interaction could include the association of a pollutant with a particular medium or substance ${ }^{19}$ or induce a chemical reaction within the device. ${ }^{20}$ At the end of the deployment, the passive sampler is analyzed through visual inspection or via advanced laboratory analytical methods. A notable advantage of passive sampling in water systems is that the deployment is easy (i.e., no specialized skills required), rapid, and usually does not require confined space entry permits. Furthermore, the continuous exposure of the passive sampler to the water column reduces the sampling errors that exist when taking discrete water samples. Consequently, passive sampling has had a significant uptake in freshwater resource settings, especially in the field of water chemistry, where both timebased and flow-based passive sampling techniques have been validated. ${ }^{19,21}$
The application of passive sampling in water and wastewater microbiology has not received much research attention, with only seven peer reviewed studies identified. ${ }^{4-6,22-25}$ Two studies have used glass bead passive samplers: one to characterize colonizing biofilms in groundwater ${ }^{22}$ and the other to monitor for pathogens in wastewater. ${ }^{25}$ VincentHubert et al. $^{23}$ trialed several passive samplers, including Zetapor membranes, nylon materials, low-density polyethylene, and polyvinylidene difluoride, for the detection of herpesviruses and noroviruses in seawater. The other four studies monitored pathogens in wastewater systems using the Moore swab, which is a piece of medical gauze that is placed in the wastewater for 1 to 7 days and is attached to a string for retrieval. ${ }^{5}$ Slight modifications to the Moore swab have been adopted by de Melo Cassemiro et al., ${ }^{24}$ who utilized Sattar and Westwood's ${ }^{4}$ method to monitor for polioviruses in wastewater. Sikorski and Levine ${ }^{6}$ recently revived the Moore swab to monitor Salmonella bacteria in surface waters and wastewaters.

Although these studies provided a proof of concept that passive samplers can be used for pathogen detection in wastewater, significant research questions remain prior to their use in WBE. First, none of the above studies evaluated the sensitivity of the devices for detecting pathogens in wastewater nor how this sensitivity compares to traditional auto-sampling or grab sampling techniques. Second, the above papers do not explore whether the accumulation of pathogens on the passive samplers is correlated with the concentration of pathogens in the water column, which is essential information if passive samplers are to help quantify the number or the level of infections in sub-catchments.

The aim of this research study was to provide a proof of concept for the use of simple passive samplers for the detection of SARS-CoV-2 in wastewaters from low case number settings, which would be relevant for surveillance aiming at early detection use cases. This study validated the sensitivity of the passive samplers against traditional wastewater monitoring methods and assessed the potential of passive samplers at a variety of scales, ranging from single allotments to small-scale and large-scale sewage treatment plants.

\section{METHODOLOGY}

2.1. Selection of Passive Materials. Three commonly available and cheap materials for passive sampling of viruses in wastewater were used: $75 \mathrm{~mm}$ by $75 \mathrm{~mm}$ medical gauze swabs (i.e., as for the original Moore swab; ${ }^{4-6,23,24}$ Handy 8 ply, BSN Medical, Germany), typical laboratory grade electronegative filter membranes (cellulose nitrate filter, 11406-47-ACN, Sartorius, Germany, similar to refs 23 and 26), and cotton buds (Swisspers, China), which were especially attractive due to their small footprint and ease of use in subsequent extraction steps.

2.2. Design of Passive Sampler Units. We initially used the traditional Moore swab design (medical gauze attached to a string), but the ragging rates were high, thus limiting potential interactions between the virus in the wastewater and the passive sampler. Ragging is the accumulation of solid wastewater materials of greater than $5 \mathrm{~mm}$, for example, food scraps, toilet tissues, and other sanitary products. As such, we opted to place the passive samplers inside housings to minimize ragging. The design of the housing for the passive samplers varied depending on the scale of the site in question and our experience as the study progressed regarding ragging rates. In total, four designs were developed and trialed (Figure 


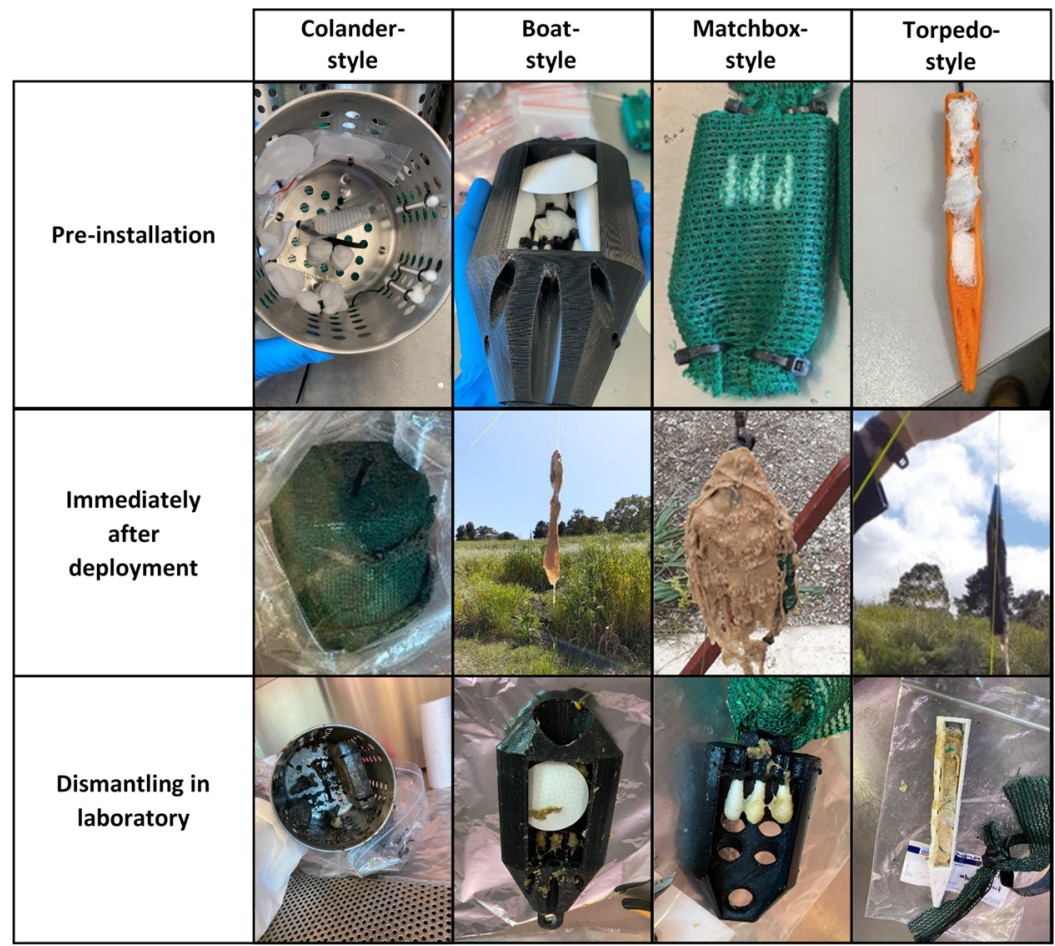

Figure 1. Four designs of passive sampler units: colander (far left column), boat (mid left column), matchbox (mid right column), and torpedo (far right column), before deployment (top row), directly after deployment (middle row), and during processing in the laboratory (bottom row).

Table 1. Site Characteristics of the Eight Field Trials Conducted, Noting the Upstream Population Contributing to Each Sampling Location, the Style(s) of Passive Sampling Units Used, the Deployment Durations, the Number of Deployments Trialed at Each Site, and the Type (if Any) of Paired Traditional Wastewater Sampling

\begin{tabular}{|c|c|c|c|c|c|}
\hline \multirow[b]{2}{*}{ site name } & \multirow[b]{2}{*}{$\begin{array}{l}\text { sewer type, sewer } \\
\text { diameter }\end{array}$} & \multirow[b]{2}{*}{$\begin{array}{c}\text { upstream } \\
\text { population }\end{array}$} & \multicolumn{2}{|c|}{ passive sampler } & \multirow[b]{2}{*}{$\begin{array}{l}\text { paired traditional wastewater sampling } \\
\text { during deployment period? }\end{array}$} \\
\hline & & & $\begin{array}{c}\text { deployment } \\
\text { duration [hours] }\end{array}$ & $\begin{array}{l}\text { number of deployments }[d] \\
\text { (sampler unit/housing used) }\end{array}$ & \\
\hline aged care & $\begin{array}{l}\text { at-site } \\
150 \mathrm{~mm}\end{array}$ & 260 & $3-7$ & $\begin{array}{l}d=12 \\
(6 \text { matchbox, } 6 \text { torpedo })\end{array}$ & yes $^{c}$ \\
\hline Sewer $48 \mathrm{~K}$ & $\begin{array}{l}\text { trunk sewer } \\
720 \mathrm{~mm}\end{array}$ & $48.9 \mathrm{~K}$ & 24 & $\begin{array}{l}d=5 \\
(4 \text { boat, } 1 \text { torpedo })\end{array}$ & no \\
\hline Sewer $49 \mathrm{~K}$ & $\begin{array}{l}\text { trunk sewer } \\
720 \mathrm{~mm}\end{array}$ & $49.2 \mathrm{~K}$ & 24 & $\begin{array}{l}d=5 \\
(4 \text { boat, } 1 \text { torpedo })\end{array}$ & no \\
\hline Sewer $70 \mathrm{~K}$ & $\begin{array}{l}\text { trunk sewer } \\
800 \mathrm{~mm}\end{array}$ & $70 \mathrm{~K}$ & 24 & $\begin{array}{l}d=5 \\
(4 \text { boat, } 1 \text { torpedo) }\end{array}$ & no \\
\hline Sewer $95 \mathrm{~K}$ & $\begin{array}{l}\text { trunk sewer } \\
1140 \mathrm{~mm}\end{array}$ & $95 \mathrm{~K}$ & 24 & $\begin{array}{l}d=5 \\
(4 \text { boat, } 1 \text { torpedo) }\end{array}$ & no \\
\hline Sewer $491 \mathrm{~K}$ & $\begin{array}{l}\text { trunk sewer } \\
2950 \mathrm{~mm}\end{array}$ & $491 \mathrm{~K}$ & 24 & $\begin{array}{l}d=5 \\
(4 \text { boat, } 1 \text { torpedo) }\end{array}$ & no \\
\hline Colac STP & $\mathrm{STP}^{a}$ & $13 \mathrm{~K}$ & 24 & $\begin{array}{l}d=10 \\
(10 \text { colander })\end{array}$ & yes $^{d}$ \\
\hline $\mathrm{WTP}^{b}$ & $\mathrm{STP}^{a}$ & $2.2 \mathrm{M}$ & 24 & $\begin{array}{l}d=11 \\
(11 \text { colander })\end{array}$ & yes $^{e}$ \\
\hline
\end{tabular}

${ }^{a}$ STP - sewage treatment plant. ${ }^{b}$ WTP - Western Treatment Plant, Melbourne's largest STP. ${ }^{c}$ Flow-weighted composite from grab sampling every 10 to $30 \mathrm{~min} .{ }^{d}$ Time-averaged composite refrigerated autosampler. ${ }^{e}$ Flow-weighted composite refrigerated autosampler.

1), with each sampler having an internal metal weight to ensure that it was submerged. Each passive sampler unit was fixed to a secure anchor point with a $3 \mathrm{~mm}$ diameter rope.

2.2.1. Colander-Style Units. A larger passive sampling device (120 mm diameter and $135 \mathrm{~mm}$ high) made from a readily available cutlery colander (ORDNING, IKEA, Sweden) was used for sampling at sewage treatment plants (Figure 1). Each colander contained triplicates of each passive sampling material, tied in place using cable ties (note that the electronegative membranes were first placed inside a hollow Perspex holder to protect them from damage and to ensure that it remained in contact with wastewater flow). The colander was wrapped in shade cloth (Rainforest 90\% UV shade cloth, Coolaroo, Australia) to make the surface of the device smooth, avoid excessive gross pollutants from entering the device, and hence ensure that mass transfer efficiencies were maintained. 
2.2.2. Boat-Style Units. Medium-sized passive sampler housings (170 mm long, $80 \mathrm{~mm}$ wide, and $37 \mathrm{~mm}$ high) were designed for sewer-line installations (i.e., pipes $>500 \mathrm{~mm}$ in diameter) (Figure 1). These housings were created using a 3D printer (Creator Pro, FlashForge, China), files for which are available in the Supporting Information section. As with the colander design, there were multiple entry points for the wastewater, including at the front, top, and bottom. Each boat was wrapped in shade cloth and contained triplicates of each of the passive sampling materials.

2.2.3. Matchbox-Style Units. Small housings (70 mm long, $40 \mathrm{~mm}$ wide, and $10 \mathrm{~mm}$ high) were designed for installation in sewer pipes less than or equal to $150 \mathrm{~mm}$ in diameter and 3D-printed (files available in the Supporting Information section). Each matchbox style sampler had multiple entry points for the wastewater at the front, top, and on the bottom (Figure 1). They contained three cotton buds, hot-glued into location, and were wrapped in shade cloth to prevent ragging (Figure 1).

2.2.4. Torpedo-Style Units. A new sampler was designed to resemble a torpedo (Figure 1), to allow for any rags caught on the anchor rope to skim off the housing. This sampler was again 3D printed and had multiple entry points for wastewater to interact with the passive samplers (front, top, sides, and bottom; Figure 1). Each contained up to six passive sampling materials (sometimes daisy-chained to have three replicates of each material in two boats) and was again wrapped in shade cloth. To further reduce ragging, hot-glue and tape were used to attach the shade cloth instead of cable ties.

2.3. Study Sites, Passive Sampler Deployment, and Traditional Wastewater Sampling. 2.3.1. Study Sites. Eight sites in Victoria, Australia (see Figure S1, Supporting Information) were used in this study to represent different scales, ranging from systems that collect the wastewaters of 260 residents and staff in an aged care facility to Melbourne's largest sewage treatment plant that collects wastewater from over 2 million inhabitants (Table 1). These sites were chosen due to having known cases of COVID-19 upstream on the downward slope of the second wave of infections in Victoria (June 2020 to November 2020). This was purposive to provide field conditions, which would simulate low viral shedding levels similar to those that might occur in an early detection scenario relevant for Australia's extremely low prevalence setting with no or few cases of community transmission.

All passive sampling deployments in this study were conducted between September 30, 2020 to the end of October 2020. During this period, the Department of Health and Human Services website ${ }^{27}$ reports that the number of active and known cases in Victoria decreased from 228 (September 30 ) to just 23 (October 31) in a total population of $6,694,900,{ }^{28}$ representing rates of illness starting at 0.34 per 10,000 population and ending at 0.034 per 10,000 population. While these numbers and rates represent minimum estimates, the high clinical testing rates in Victoria provide confidence in these data $(3,574,000$ clinical tests had been conducted in Victoria by November 2020).

Seven of the eight sites were in metropolitan Melbourne, while one was in Colac, a small town in regional Victoria (see Figure S1, Supporting Information). The aged care facility ("aged care") had a known outbreak and was in lockdown, with the last case diagnosed 11 days prior to the initiation of sampling with a 22 day duration of sampling. Recent cases including other aged care outbreaks were known to be within the area of Melbourne, and much of its wastewater is treated at the Western Sewage Treatment Plant ("WTP"). The five trunk sewer sampling sites (sites Sewer $48 \mathrm{~K}$, Sewer $49 \mathrm{~K}$, Sewer 70 $\mathrm{K}$, Sewer $95 \mathrm{~K}$, and Sewer $491 \mathrm{~K}$ ) are all on the same wastewater line that then connect to WTP (see Figure S1, Supporting Information) and therefore are expected to have some cases in these sub-catchments within the expected shedding period. Furthermore, the aged care facility drains into the same sewer line between Sewer $48 \mathrm{~K}$ and Sewer $49 \mathrm{~K}$ (see Figure S1, Supporting Information). The Colac STP also had a known outbreak, with the last known case identified more than 4 weeks prior to initiation of sampling, with a sampling duration of 16 days.

2.3.2. Passive Sampler Deployment and Traditional Wastewater Sampling Strategies. For the five trunk sewer sites (Sewer $48 \mathrm{~K}$, Sewer $49 \mathrm{~K}$, Sewer $70 \mathrm{~K}$, Sewer $95 \mathrm{~K}$, and Sewer $491 \mathrm{~K}$ ), paired wastewater sampling using traditional approaches was not possible due to cost and logistical constraints. At these sites, passive samplers were deployed and retrieved $24 \mathrm{~h}$ later. In total, five $24 \mathrm{~h}$ long deployments were performed, representing data acquired from both the boat-style (four deployments) and the torpedo-style units (one deployment).

Traditional grab or automatic wastewater sampling was conducted at the other three sites paired alongside the passive sampler deployments. At the STPs, refrigerated automatic samplers were available, and these were programmed to take samples across the entire passive sampler deployment period. For the WTP, 12 discrete samples were taken each day, where one bottle was filled every $2 \mathrm{~h}$, using four pulses of water, each $30 \mathrm{~min}$ apart. Using the measured flow at the inlet of the WTP, these samples were then combined to create a flow-weighted composite sample. At this site, both discrete and composite samples were used to assay for SARS-CoV-2. At the Colac STP, a time-averaged composite sample was created in situ, where an equal pulse of water was distributed into a single container every $15 \mathrm{~min}$ across the day.

The site serving the aged care facility was the smallest with a $150 \mathrm{~mm}$ diameter sewer. It was not possible to install permanent auto-sampling equipment at this site (manhole and pipe too small for equipment), and hence, frequent grab samples were taken across the duration of the passive sampler deployment. To ensure that representative wastewater samples were taken at this site, we opted for intensive and frequent sampling to occur during the period of passive sampler deployment. We also considered potential occupational health and safety risks and limited the sampling and passive sampler deployment durations to be between 3 and $7 \mathrm{~h}$ in length (i.e., overnight sampling was not conducted). This also allowed us to maintain constant visual contact with the passive sampler during the deployments to mitigate any possible creation of blockages or backflow issues (none were observed). For the 3 $\mathrm{h}$ deployment duration, we collected grab samples every 10 min from the sewer, which were then pooled using flow weightings to make composite samples. For the $7 \mathrm{~h}$ deployments, the first and last hours of sampling were intensive (10 min intervals) because these were also at periods of high toilet use (i.e., after breakfast, after lunch, or after dinner), while the middle hours were less intense (every 30 $\mathrm{min}$ ). At this site, both composite and discrete samples were used for SARS-CoV-2 assays.

2.4. Laboratory Analysis. In total, 183 traditionally collected wastewater samples and 245 passive sampling 
materials were pre-processed, extracted, and analyzed for SARS-CoV-2 using the procedure outlined below.

2.4.1. Pre-Processing and Storage. All samples were transported to the laboratory on ice and pre-processed on the day of collection. Wastewater samples were processed similarly to others in the literature, ${ }^{26}$ where $50 \mathrm{~mL}$ of wastewater was filtered through a $47 \mathrm{~mm}$ diameter, $0.45 \mu \mathrm{m}$ pore size, electronegative membrane (Satorius, Germany). RNA extraction from these filters typically occurred directly after filtration, but some were stored at $-80^{\circ} \mathrm{C}$ until extraction was possible.

Immediately after retrieval, passive sampling units were cleared of all obvious ragging materials. Passive sampling units were dismantled on the day of retrieval, resulting in up to nine individually stored passive samplers for each site, each day. Electronegative membranes and cotton buds were either used immediately for RNA extraction or directly frozen at $-80{ }^{\circ} \mathrm{C}$ until extraction was possible. Gauzes were either directly frozen at $-80{ }^{\circ} \mathrm{C}$ or immediately eluted by placing them in a sterile stomacher bag with $10 \mathrm{~mL}$ of $1 \times$ sterile phosphate buffer solution mixed with $0.05 \%$ Tween 80 (Fisher, T164) and $0.001 \%$ Y-30 antifoam emulsion (Sigma catalog no. A$\left.5758^{29}\right)$. After stomaching at $200 \mathrm{rpm}$ for $2 \mathrm{~min}$, the gauze was moved to one side of the bag, which was held on an angle. After squeezing the remaining liquid from the gauze, the elution buffer was then filtered through a $47 \mathrm{~mm}$ diameter, $0.45 \mu \mathrm{m}$ pore size, electronegative membrane. These were used immediately for extraction.

2.4.2. RNA Extraction. The electronegative membranes and cotton buds were directly placed into $2 \mathrm{~mL}$ garnet-type beadbeating tubes and then processed using a Qiagen RNeasy PowerMicrobiome kit (Qiagen, Germany), with the following modifications: (1) $100 \mu \mathrm{L}$ of phenol:chloroform:isoamyl (25:24:1, pH 6.5-8.0) was added to the bead-beating tube before adding the sample, (2) beat-beating for $30 \mathrm{~s}$ at $4 \mathrm{~m} / \mathrm{s}$ (MP-Bio, USA), (3) DNase treatment was conducted for 15 min, and (4) final elution was done using $50 \mu \mathrm{L}$ of DEPC water (Sigma-Aldrich, Germany), passed through twice to ensure maximum yield. At least one method extraction blank was conducted on each day that extractions were conducted. On some occasions, the Qiagen RNeasy PowerMicrobiome kits were not available so we used the Macherey-Nagel NucleoSpin RNA Stool kit (Macherey-Nagel, Germany) as per manufacturer's instructions. Our initial validation studies showed that this produces a higher recovery rate (data not shown). Passive sampling materials and wastewater samples collected using traditional techniques on any given day were processed using the same kit.

2.4.3. Reverse Transcription and $q P C R$. The SARS-CoV-2 real-time RT-PCR assay (PerkinElmer, USA; hereafter referred to as the $\mathrm{PE}$ assay), which is a combined reverse transcription and TaqMan-based qPCR, was used to detect both the nucleocapsid N (via the FAM fluorophore) and the ORF-1ab (via the ROX fluorophore) genes of the SARS-CoV-2 virus. After significant testing, our process included slight variations from that of the PE manufacturer's recommendation: $5 \mu \mathrm{L}$ of template was used in each reaction together with $10 \mu \mathrm{L}$ of the PE master mix and $15 \mu \mathrm{L}$ of ultrapure DNase/RNAase free water (Invitrogen, USA). During the early stages of the experiment, between three and five technical replicates were used to help explore the between-replicate variability, after which we used duplicates. We always ran duplicate no template controls, which were always negative, and standard curves using five dilutions of the Twist synthetic SARS-CoV-2 RNA control 1 (GenBank ID: MT007544.1, Cat no: 102019), resulting in very high coefficients of determination $\left(R^{2}>0.99\right)$ and consistent intercepts (mean for $\mathrm{N}$ gene: 43.6; ORF-1ab gene: 42.5) and slopes (mean for $\mathrm{N}$ gene: -3.47 ; ORF-1ab gene: -3.38$)$ resulting in acceptable qPCR efficiencies $(E=94$ and $98 \%$, respectively). The $\mathrm{qPCR}$ protocol and standard curves are available in the Supporting Information. The manufacturer suggests that their MS2 phage internal control (detected via the VIC fluorophore) is added to samples prior to bead-beating. However, the bead-beating appeared to shear the MS2 RNA, limiting its use as a full extraction control, and hence, we instead added the MS2 RNA after the bead-beating step. According to the manufacturer specifications, we re-ran samples that were inhibited according to this MS2 control at 1:10 dilutions (and if still inhibited at 1:33); this resulted in $34 \%$ of our samples being run at least 1:10 dilutions of the template. All assays were run with 45 cycles on a Bio-Rad Laboratories CFX-96 qPCR machine (Bio-Rad, USA). Each amplification curve was manually inspected by the same individual and cross-checked by another. Thresholds to determine Cq values were estimated using the "auto threshold" option in the Bio-Rad CFR Maestro 1.1 program (Bio-Rad, USA, 2017) and were compared between runs for consistency.

2.4.4. Detection Limits. A gamma-irradiated preparation of a SARS-CoV-2 Australian isolate (provided by the Victorian Infectious Diseases Reference Laboratory at the Doherty Institute) and the Twist synthetic SARS-CoV-2 RNA control 1 were both used to determine our limit of quantification (LOQ) following that of refs 30-32. As recommended by the authors in ref 30, we first used our standard curve datasets to estimate that our LOQ was in the range of less than 500 copies per reaction (see the SI) and then conducted a second experiment to narrow down the concentration range and increase the number of replicates for more precise estimates of LOQ. ${ }^{30} \mathrm{We}$ thus had increased replicates for the following dilutions: 500, $100,50,20,10,5$, and 1 copies per reaction. For each dilution, we calculated the coefficient of variation of the estimated concentrations using the equation proposed by the authors in ref 30 (see the SI for details), and similar to these authors, we set our predefined variability threshold at $\mathrm{CV}=35 \%$. As shown in the SI, all dilutions down to 10 copies per reaction had CV values of less than 35\% (CV values for 5 gene copies and 1 gene copy per reaction were 50 and $115 \%$, respectively), and interpolation of the data ${ }^{31}$ resulted in an estimated LOQ of 8.9 copies per reaction or rather a $\mathrm{Cq}$ value $<40$ ( 40.3 for the $\mathrm{N}$ gene and 39.3 for the ORF-1ab gene). According to the above protocol $(50 \mathrm{~mL}$ of wastewater filtered; $50 \mu \mathrm{L}$ of extraction volume, and $5 \mu \mathrm{L}$ of template into each qPCR well), $5 \mathrm{~mL}$ of equivalent volume of wastewater was placed into each $\mathrm{qPCR}$ well. As such, we reached a LOQ of, on average, 8.9 copies per $5 \mathrm{~mL}$ of wastewater or rather 1.8 copies per $\mathrm{mL}$ of wastewater.

2.4.5. Sequence Confirmation. As a part of a side-by-side study, we sent 58 qPCR products from passive sampling materials for genomic sequencing (methodological details in the SI). In summary, all of the samples that were negative for qPCR (i.e., $\mathrm{Cq}>45$ ) were also negative by sequencing. There were 38 qPCR-positive samples sent for sequencing, which had qPCR Cq values that ranged between 44.2 and 35.7 with a mean of 38.3. The 38 qPCR-positive samples had detectable $\mathrm{N}$ genes, and these were all confirmed positive by sequencing. Of the 18 samples that had qPCR-positive ORF-1ab genes, 17 of them were also positive by sequencing. This data validates the 
Table 2. The Number of Samples Processed $(n)$ and the Percentage of These that Had Detectable Levels of SARS-CoV-2, Ordered by Sites and Sample Type ${ }^{c}$

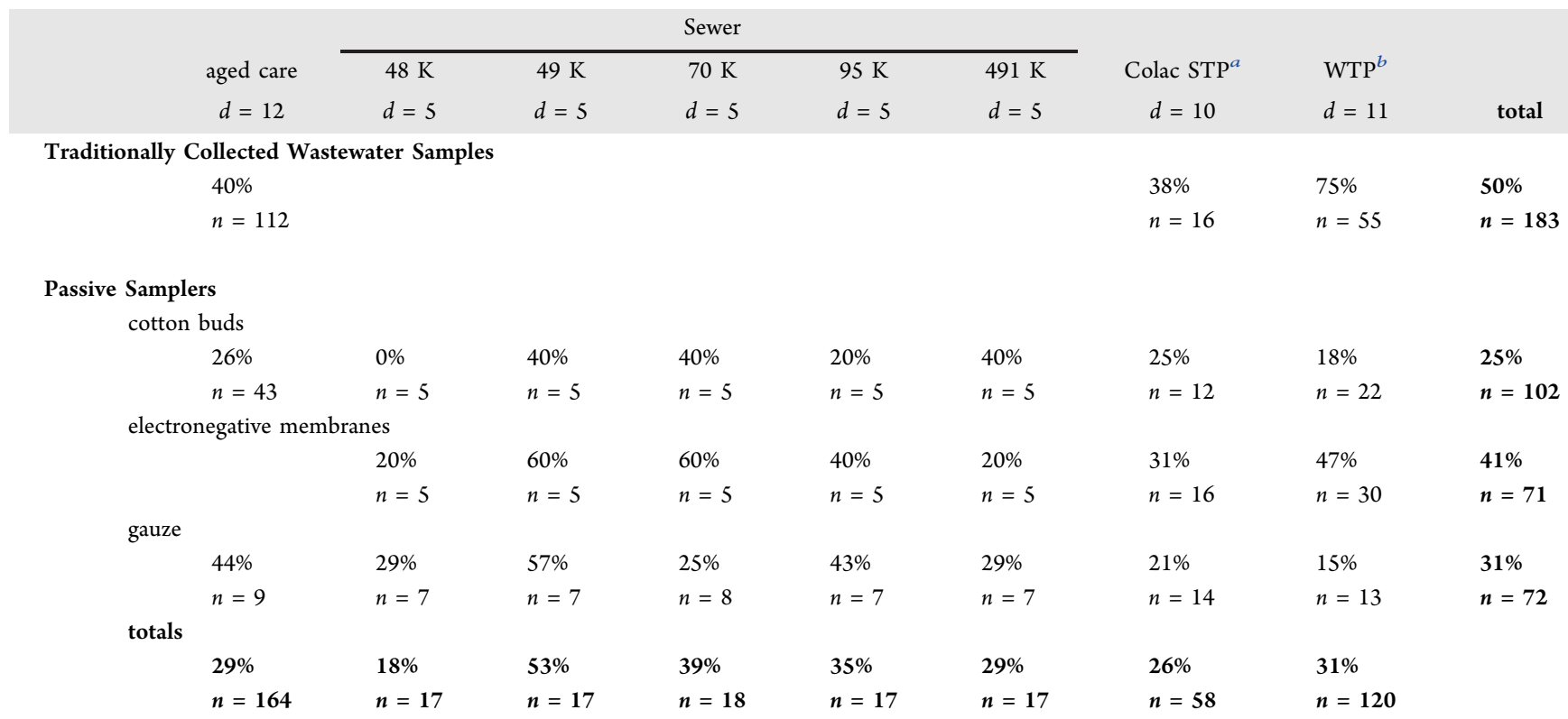

${ }^{a}$ STP - sewage treatment plant. ${ }^{b}$ WTP - Western Treatment Plant, Melbourne's largest STP. ${ }^{c}$ Empty cells indicate that the sample type was not collected at this site. Also noted is the number of days where sampling was conducted $(d)$.

ability to detect SARS-CoV-2 on passive sampling materials even in samples that had very late qPCR amplification.

2.5. Data Analysis and Comparisons. As outlined above, even samples that had detectable SARS-CoV-2 values below the LOQ $(\mathrm{Cq}>40)$ were confirmed positive by sequencing. As such, and in agreement with others, ${ }^{30}$ all samples that showed amplification of $\mathrm{N}$ or ORF-1ab genes were treated as positive for SARS-CoV-2. We used each recorded Cq value to estimate the number of copies per reaction using the stated intercepts and slopes. For the wastewater samples, these values were then divided by the amount of wastewater that was placed into each qPCR well to estimate the concentration of SARS-CoV-2 in the wastewater (copies $/ \mathrm{mL}$ ). The average of these concentrations was calculated using all individual estimates (from all replicates and dilutions) to finally estimate the number of copies per milliliter of wastewater. For the passive samplers, the copies per reaction value was divided by the proportion of RNA extract used in each qPCR well to obtain the number of copies of SARS-CoV-2 per passive sampler (copies/sampler).

We compared how often passive samplers had detectable SARS-CoV-2 to how often the concentration of SARS-CoV-2 in wastewater was above the LOQ ( $>1.8$ copy per $\mathrm{mL})$. Using this qualitative data, we computed a $2 \times 2$ frequency table.

As per authors in ref 33, the loading of viruses found on each passive sampling material should be linked to the concentrations of viruses found in the bulk wastewater. To assess this, the average daily $\log _{10}$ concentration of SARS-CoV-2 measured in the wastewater (i.e., copies per milliliter) was correlated (Pearson $r$ ) to the average $\log _{10}$ copies of SARS-CoV-2 detected on the passive samplers. A Student's $t$-test was used to determine the significance of this correlation $(p<0.05)$.

\section{RESULTS AND DISCUSSION}

3.1. Ragging Rates of Passive Sampler Units. As expected, ragging of the passive sampler units occurred throughout the study (Figure 1; middle row). The boat-style unit experienced the most significant ragging, likely because they collected along the anchor rope, slid down, and were trapped on the wide body of this unit (Figure 1). The matchbox-style unit also experienced ragging, again likely because of the wide shape (relative to the anchor rope) and catching ability of the cable ties used to fix the unit to the rope (Figure 1). The larger colander design was rarely covered in rags (Figure 1), likely because they were always installed in the intake to sewage treatment plants where the water had often been through pumps that had macerated the wastewater's contents. Finally, the torpedo-style unit experienced very little ragging, where $10 \%$ was retrieved with visible ragging materials and the front holes were blocked less than $5 \%$ of the time. While further optimization of the design could be warranted to reduce ragging and clogging of openings, these $3 \mathrm{D}$-printed devices are attractive as they are easily available, cheap, and require very low expertise to print, assemble, and deploy.

3.2. Detection of SARS-CoV-2 on Passive Samplers. Although the prevalence of COVID-19 in Victoria was low during the testing period (between 23 and 280 active cases per population of 6.7 million, representing an average estimated infection rate between 0.034 and 0.34 per 10,000 population), SARS-CoV-2 was still detectable both in traditionally collected wastewater samples and on passive sampling materials. These detections from low prevalence populations provide confidence in use of wastewater surveillance for tracking of COVID-19. Indeed, SARS-CoV-2 was detected in 50\% of the 183 traditionally collected wastewater samples (Table 2), which aligns well with the fact that all sites analyzed for water samples were chosen because there were known cases of COVID-19 upstream albeit at low levels with no recent new infections. Of the 245 passive samplers analyzed, $31 \%$ of them had detections of SARS-CoV-2 (Table 2), with a higher proportion of electronegative membranes (41\%) having detections than gauzes (31\%) or cotton buds (25\%). Overall, these results indicate that electronegative membranes, cotton buds, and gauzes can be used as passive samplers of SARS- 

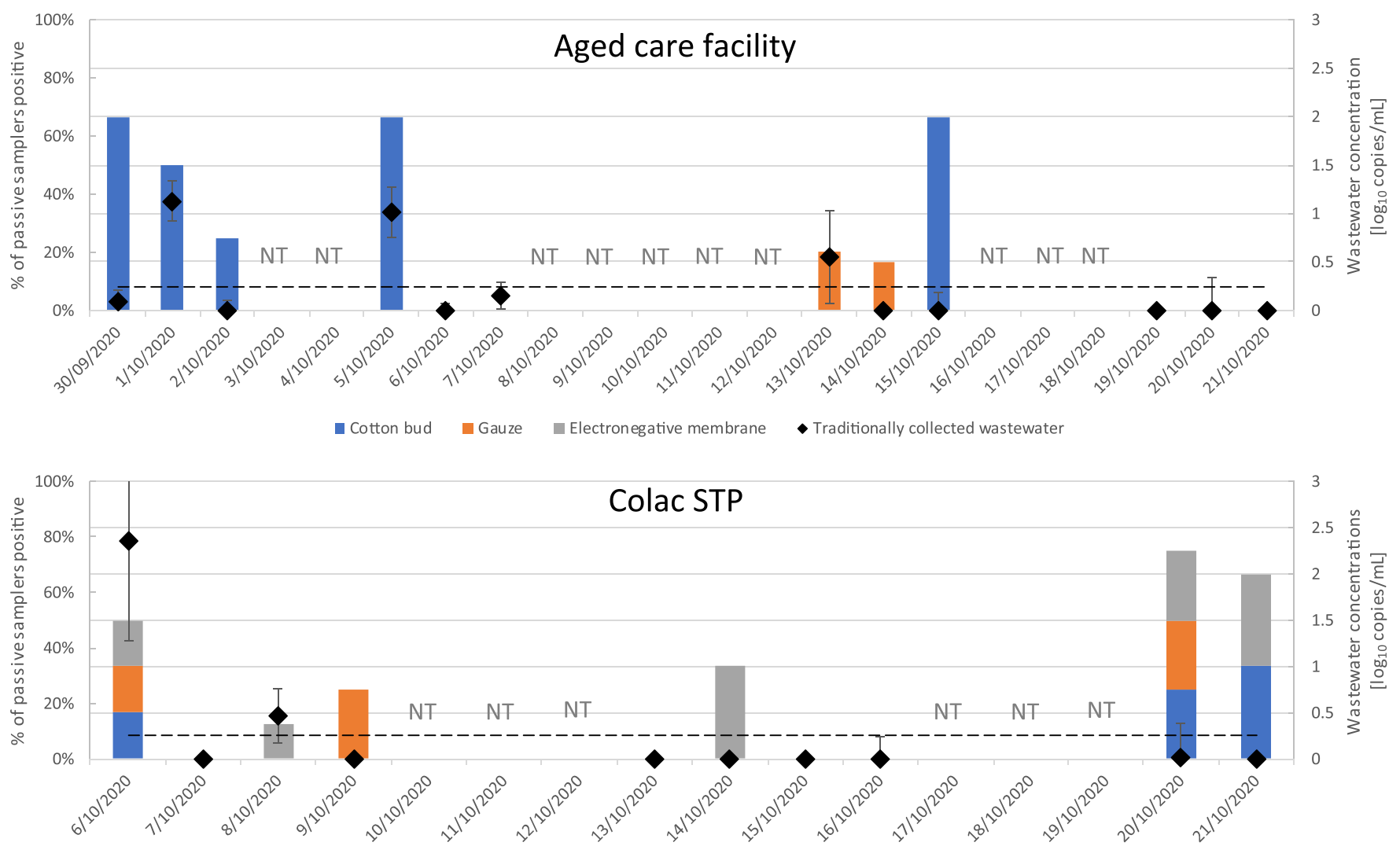

¿ Cotton bud $\quad$ Gauze Electronegative membrane • Traditionally collected wastewater

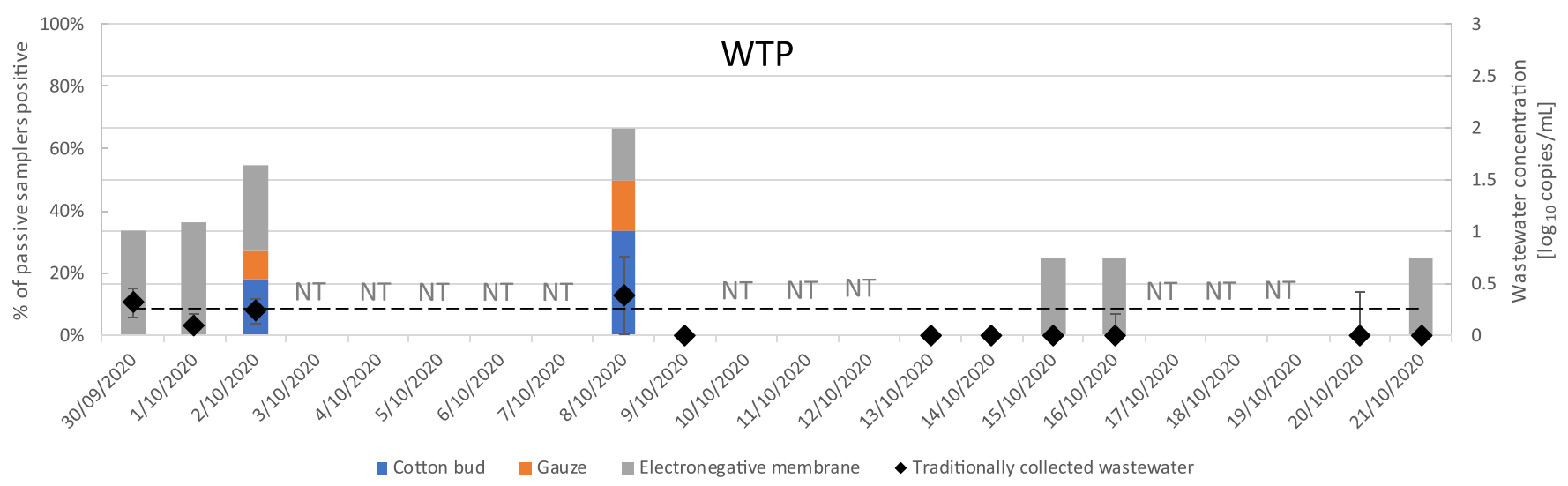

Figure 2. Detection frequency of SARS-CoV-2 in passive samplers (bar charts, left-hand axis) and average concentration of SARS-CoV-2 in wastewater using traditional methods (black diamonds, right hand axis). Error bars represent the standard error of the samples used to estimate the daily average wastewater concentrations. The height of each column represents the total percentage of passives that were positive, and each color represents the proportional contribution from each material (blue - cotton bud, orange - gauze, and gray - electronegative membrane). Passive samplers and traditional wastewater samples were always deployed/taken on the same dates and represent the same time period. Dates labeled with "NT" indicate that no tests were conducted for either traditional wastewater samples or passive samplers. Dates where bar charts are not visible indicate that no passive samplers were positive for SARS-CoV-2. The estimated LOQ for the traditionally collected wastewater samples was 1.8 gene copies per $\mathrm{mL}$ (dashed black line), and hence, black diamonds that sit below this line indicate their average daily concentration is $<$ LOQ.

CoV-2 in human wastewaters and provide the first proof of concept that one or more of these passive samplers could be prime candidates for further optimization for use in WBE of SARS-CoV-2 or other viruses more generally.

3.3. Do Results from Passive Samplers Align with Traditionally Collected Wastewater Samples? The concentrations of SARS-CoV-2 in the wastewater proximal to the aged care facility and those at the inlet of the WTP and Colac STPs were highly variable (Figure 2, black diamonds), ranging from below LOQ (1.8 gene copies $/ \mathrm{mL}$; dashed line on secondary axes in Figure 2) to over 223 copies per $\mathrm{mL}$ detected at the Colac Sewage Treatment plant on October 6, 2020. It is important to note that while Table 2 shows the total number of samples taken over the entire period of time, Figure 2 displays daily averages for the sites, resulting in a fewer daily detections as multiple wastewater samples were processed on some days at some sites.

After converting the quantitative data of SARS-CoV-2 concentrations in wastewater to presence/absence data using our confirmed LOQ of 1.8 copy per $\mathrm{mL}$ of wastewater, it was 
possible to conduct a qualitative comparison of the different monitoring methods. On all days where the average concentration of SARS-CoV-2 was greater than the LOQ of 1.8 copy per $\mathrm{mL}$, at least one of the passive samplers deployed on that same day was also positive for SARS-CoV-2 (Table 3).

Table 3. Frequency Table Reporting the Number of Days where SARS-CoV-2 Was Detected in at Least One Passive Sampler as Compared to the Number of Days where Average Wastewater Concentrations Were at or above 1.8 copies/mL

\begin{tabular}{|c|c|c|c|c|}
\hline & & \multicolumn{3}{|c|}{ passive samplers } \\
\hline & & $\begin{array}{l}\text { days with } \\
\text { at least } \\
\text { one } \\
\text { detection }\end{array}$ & $\begin{array}{c}\text { days } \\
\text { with no } \\
\text { detection }\end{array}$ & total \\
\hline \multirow{3}{*}{$\begin{array}{l}\text { wastewater samples } \\
\text { collected using } \\
\text { traditional } \\
\text { methods }\end{array}$} & days with avg. conc. & 7 & 0 & 7 \\
\hline & $\begin{array}{l}\text { days with avg. conc. } \\
<1.8 \text { copy } / \mathrm{mL}\end{array}$ & 13 & 13 & 26 \\
\hline & total & 20 & 13 & 33 \\
\hline
\end{tabular}

Moreover, there were 13 days where the traditional wastewater sampling failed to detect SARS-CoV-2, while at least one passive sampler had detectable levels (Table 3). This might reflect the continuous contact that the passive samplers have with the sewage, which was not the case for the traditional wastewater sampling methods, even though they took samples very frequently (every 10 and 15 to $30 \mathrm{~min}$ ). This work demonstrates for the first time the potential for using passive samplers for WBE and suggests that the passive samplers are sensitive to alternate monitoring methods for detection of SARS-CoV-2 in wastewater.

3.4. Do the Levels of SARS-CoV-2 Captured on the Passive Samplers Relate to the Concentrations Seen in the Wastewater? Comparing the loading of SARS-CoV-2 on the passive sampler (i.e., copies per passive sampling material) to the concentrations of SARS-CoV-2 in the traditionally collected wastewater samples provides useful information about the association rates of the virus to the passive materials. ${ }^{33}$ When pooling the three sites that had co-collected traditional and passive samples (aged care, Colac, and Western STPs), a statistically significant correlation was observed between the daily average $\log _{10}$ concentration of SARS-CoV2 measured in the wastewater and the average $\log _{10}$ copies of SARS-CoV-2 on the passive samplers $(p=0.0008$ and $R=$ 0.55; Table S2 in the Supporting Information). Although these results provide a necessary proof of concept that higher wastewater concentrations yield higher accumulation of SARSCoV-2 on passive samplers, further work is required to optimize the laboratory methodologies for each passive sampler prior to any further quantitative inference.

3.5. General Discussion. We demonstrate that passive samplers are an effective and scalable option for monitoring SARS-CoV-2 in wastewater systems, providing evidence that passive samplers have the potential for wider adoption in WBE. This study shows that passive samplers were able to detect SARS-CoV-2 in wastewaters from a population that has just a few active COVID-19 cases. Indeed, targeted surveillance for the aged care facility and Colac STP show detection of viral fragments on passive samplers even though there were no active cases and only a few people likely in their late shedding period. Our data directly demonstrates that when the daily average SARS-CoV-2 concentration in the wastewater equals or exceeds our LOQ of 1.8 copy per $\mathrm{mL}$, at least one of the passive samplers deployed at the same site on the same day was positive. Further, the statistically significant correlation between the concentrations of SARS-CoV-2 in the wastewater and the concentrations found on the passive samplers further demonstrates that these samplers have the potential to provide meaningful quantitative data.

There are several aspects of this research which should be further strengthened as we begin to unlock the potential of passive samplers for SARS-CoV-2 wastewater surveillance applications. For instance, linking the results of these passive sampling materials with spatially disaggregated clinical datasets from each site over the deployment duration will provide further insights into their effectiveness. Increasing the sample size of our traditional vs passive sampler comparisons is also deemed essential, noting that this paper used a sample size of 33 days of sampling for these direct comparisons. Our work did not fully uncover the strengths and weaknesses of each individual passive sampling material, and instead, we combined the datasets to answer our research questions. Further work should be conducted on each passive sampling material, answering questions such as (1) what is the association rate of SARS-CoV-2 with each passive sampling material, (2) what are their maximum association capacities, and hence maximum deployment durations, and (3) what are the most optimal elution, extraction, and assay methods for each passive sampling material. Furthermore, this study did not calculate the concentration of SARS-CoV-2 per mass, per volume, or per area of each passive sampling material and instead estimated the total amount of virus captured by each passive sampler. Together with flow and dilution rates, concentrations of SARSCoV-2 on passive sampling materials would be required to estimate the number of infected individuals within a specific sub-catchment. We also did not determine the detection limits for each material, which is also important for moving to quantitative results.

This paper provides evidence that easily available and cheap materials (electronegative membranes, cotton buds, and medical gauze) can be used as passive samplers of wastewaters with low levels of SARS-CoV-2. A suitable 3D-printed housing unit was developed that protected against ragging, maintaining mass transfer efficiencies between the wastewater and the passive sampling materials. The freely available housing unit design that can be made with commonly available $3 \mathrm{D}$ printers is quick to assemble and easy to deploy.

\section{ASSOCIATED CONTENT}

\section{Supporting Information}

The Supporting Information is available free of charge at https://pubs.acs.org/doi/10.1021/acs.est.1c01530.

(1) The map and population sizes for each sampling site, (2) details of the qPCR process, including standard curves for each experiment and detection limit assays, (3) methods used for sequencing confirmation of qPCRpositive passive samplers, (4) images of the three housings developed in this paper, and (5) table showing the daily averaged concentrations of SARS-CoV- 2 found in wastewater samples and the average loading on the passive sampler materials (PDF) 


\section{AUTHOR INFORMATION}

\section{Corresponding Author}

David T. McCarthy - Environmental and Public Health Microbiology Lab (EPHM Lab), Department of Civil Engineering, Monash University, Clayton, Victoria 3800, Australia; ๑ orcid.org/0000-0001-8845-6501;

Email: david.mccarthy@monash.edu

\section{Authors}

Christelle Schang - Environmental and Public Health Microbiology Lab (EPHM Lab), Department of Civil Engineering, Monash University, Clayton, Victoria 3800, Australia

Nicolas D. Crosbie - Melbourne Water Corp, Docklands, Victoria 3001, Australia

Monica Nolan - Department of Health, Victoria Department of Health and Human Services, Melbourne, Victoria 3000, Australia

Rachael Poon - Department of Health, Victoria Department of Health and Human Services, Melbourne, Victoria 3000, Australia

Miao Wang - Environmental and Public Health Microbiology Lab (EPHM Lab), Department of Civil Engineering, Monash University, Clayton, Victoria 3800, Australia

Aaron Jex - The Walter and Eliza Hall Institute of Medical Research, Parkville, Victoria 3052, Australia; The University of Melbourne, Parkville, Victoria 3010, Australia

Nijoy John - The Walter and Eliza Hall Institute of Medical Research, Parkville, Victoria 3052, Australia; The University of Melbourne, Parkville, Victoria 3010, Australia

Louise Baker - The Walter and Eliza Hall Institute of Medical Research, Parkville, Victoria 3052, Australia; The University of Melbourne, Parkville, Victoria 3010, Australia

Peter Scales - The University of Melbourne, Parkville, Victoria 3010, Australia; $\odot$ orcid.org/0000-0002-8033-3686

Jonathan Schmidt - South East Water, Frankston, Victoria 3199, Australia

Bruce R. Thorley - Victorian Infectious Diseases Reference Laboratory, Royal Melbourne Hospital at the Peter Doherty Institute for Infection and Immunity, Melbourne, Victoria 3000, Australia

Kelly Hill - Water Research Australia, Adelaide 5000, South Australia

Arash Zamyadi - Water Research Australia, Docklands, Victoria 3001, Australia

Chi-Wen Tseng - Environmental and Public Health Microbiology Lab (EPHM Lab), Department of Civil Engineering, Monash University, Clayton, Victoria 3800, Australia

Rebekah Henry - Environmental and Public Health Microbiology Lab (EPHM Lab), Department of Civil Engineering, Monash University, Clayton, Victoria 3800, Australia

Peter Kolotelo - Environmental and Public Health Microbiology Lab (EPHM Lab), Department of Civil Engineering, Monash University, Clayton, Victoria 3800, Australia

Jeroen Langeveld - Department of Water Management, TU Delft, Delft CN 2628, The Netherlands;

Partners4UrbanWater, Nijmegen $6532 \mathrm{ZV}$, The Netherlands

Remy Schilperoort - Partners4UrbanWater, Nijmegen 6532 ZV, The Netherlands
Baiqian Shi - Environmental and Public Health Microbiology Lab (EPHM Lab), Department of Civil Engineering, Monash University, Clayton, Victoria 3800, Australia

Steve Einsiedel - ALS Hydrographics, Scoresby, Victoria 3179, Australia

Michael Thomas - Barwon Water, Geelong, Victoria 3220, Australia

James Black - Department of Health, Victoria Department of Health and Human Services, Melbourne, Victoria 3000, Australia

Simon Wilson - Melbourne Water Corp, Docklands, Victoria 3001, Australia

Complete contact information is available at:

https://pubs.acs.org/10.1021/acs.est.1c01530

\section{Notes}

The authors declare no competing financial interest.

\section{ACKNOWLEDGMENTS}

We gratefully acknowledge the support of the Victoria Department of Health and Water Research Australia's ColoSSoS program, especially the contributors to the Victorian node. We would also like to express our thanks to the owners and staff at the multiple facilities where sampling was undertaken, and in particular, the aged care facility. We appreciate Julian Druce, VIDRL, for providing the gammairradiated SARS-CoV-2. A.J. is supported by the NHMRC Career Development Fellowship - APP1126395 and Water Research Australian Project WaterRA Project 2064/20. The Walter and Eliza Hall Institute acknowledges support through the Victorian State Government Operational Infrastructure Support and Australian Government National Health and Medical Research Council Independent Research Institute Infrastructure Support Scheme. The project leveraged existing equipment from an Australian Research Council Linkage Project (LP160100408).

\section{REFERENCES}

(1) Dunn, G.; Klapsa, D.; Wilton, T.; Stone, L.; Minor, P. D.; Martin, J. Twenty-Eight Years of Poliovirus Replication in an Immunodeficient Individual: Impact on the Global Polio Eradication Initiative. PLoS Pathog. 2015, 11, No. e1005114.

(2) Alexander, J. P., Jr.; Gary, H. E., Jr.; Pallansch, M. A. Duration of poliovirus excretion and its implications for acute flaccid paralysis surveillance: a review of the literature. J. Infect. Dis. 1997, 175, S17682.

(3) Sinclair, R. G.; Choi, C. Y.; Riley, M. R.; Gerba, C. P. Pathogen surveillance through monitoring of sewer systems. Adv. Appl. Microbiol. 2008, 65, 249-269.

(4) Sattar, S. A.; Westwood, J. C. Isolation of apparently wild strains of poliovirus type 1 from sewage in the Ottawa area. Can. Med. Assoc. J. 1977, 116, 25-27.

(5) Moore, B. The detection of enteric carriers in towns by means of sewage examination. J. Royal Sanit. Inst. 1951, 71, 57-60.

(6) Sikorski, M. J.; Levine, M. M. Reviving the "Moore Swab": a Classic Environmental Surveillance Tool Involving Filtration of Flowing Surface Water and Sewage Water To Recover Typhoidal Salmonella Bacteria. Appl. Environ. Microbiol. 2020, 86, e00060e00020.

(7) Kitajima, M.; Ahmed, W.; Bibby, K.; Carducci, A.; Gerba, C. P.; Hamilton, K. A.; Haramoto, E.; Rose, J. B. SARS-CoV-2 in wastewater: State of the knowledge and research needs. Sci. Total Environ. 2020, 739, 139076-139076.

(8) Jones, D. L.; Baluja, M. Q.; Graham, D. W.; Corbishley, A.; McDonald, J. E.; Malham, S. K.; Hillary, L. S.; Connor, T. R.; Gaze, 
W. H.; Moura, I. B.; Wilcox, M. H.; Farkas, K. Shedding of SARS$\mathrm{CoV}-2$ in feces and urine and its potential role in person-to-person transmission and the environment-based spread of COVID-19. Sci. Total Environ. 2020, 749, 141364.

(9) Orive, G.; Lertxundi, U.; Barcelo, D. Early SARS-CoV-2 outbreak detection by sewage-based epidemiology. Sci. Total Environ. 2020, 732, 139298 .

(10) Hart, O. E.; Halden, R. U. Computational analysis of SARSCoV-2/COVID-19 surveillance by wastewater-based epidemiology locally and globally: Feasibility, economy, opportunities and challenges. Sci. Total Environ. 2020, 730, 138875.

(11) Randazzo, W.; Truchado, P.; Cuevas-Ferrando, E.; Simón, P.; Allende, A.; Sánchez, G. SARS-CoV-2 RNA in wastewater anticipated COVID-19 occurrence in a low prevalence area. Water Res. 2020, 181, $115942-115942$.

(12) Wu, Y.; Guo, C.; Tang, L.; Hong, Z.; Zhou, J.; Dong, X.; Yin, H.; Xiao, Q.; Tang, Y.; Qu, X.; Kuang, L.; Fang, X.; Mishra, N.; Lu, J.; Shan, H.; Jiang, G.; Huang, X. Prolonged presence of SARS-CoV-2 viral RNA in faecal samples. Lancet Gastroenterol. Hepatol. 2020, 5, 434-435.

(13) Gupta, S.; Parker, J.; Smits, S.; Underwood, J.; Dolwani, S. Persistent viral shedding of SARS-CoV-2 in faeces - a rapid review. medRxiv 2020, DOI: 10.1101/2020.04.17.20069526.

(14) Ahmed, W.; Angel, N.; Edson, J.; Bibby, K.; Bivins, A.; O’Brien, J. W.; Choi, P. M.; Kitajima, M.; Simpson, S. L.; Li, J.; Tscharke, B.; Verhagen, B.; Smith, W. J. M.; Zaugg, J.; Dierens, L.; Hugenholtz, P.; Thomas, K. V.; Mueller, J. F. First confirmed detection of SARS-CoV2 in untreated wastewater in Australia: A proof of concept for the wastewater surveillance of COVID-19 in the community. Sci. Total Environ. 2020, 728, 138764.

(15) Hassard, F.; Lundy, L.; Singer, A. C.; Grimsley, J.; Di Cesare, $\mathrm{M}$. Innovation in wastewater near-source tracking for rapid identification of COVID-19 in schools. Lancet Microbe 2021, 2, e4e5.

(16) Langergraber, G.; Alex, J.; Weissenbacher, N.; Woerner, W.; Ahnert, M.; Frehmann, T.; Halft, N.; Hobus, I.; Plattes, M.; Spering, V.; Winkler, S. Generation of diurnal variation for influent data for dynamic simulation. Water Sci. Technol. 2008, 57, 1483-1486.

(17) Metcalf \& Eddy; Burton, F. L.; Stensel, H. D.; Tchobanoglous, G. Wastewater engineering : treatment and reuse; Fourth Ed.; revised by George Tchobanoglous, Franklin L. Burton, H. David Stensel.: McGraw-Hill: Boston, 2003.

(18) Aymerich, I.; Acuña, V.; Ort, C.; Rodríguez-Roda, I.; Corominas, L. Fate of organic microcontaminants in wastewater treatment and river systems: An uncertainty assessment in view of sampling strategy, and compound consumption rate and degradability. Water Res. 2017, 125, 152-161.

(19) Birch, H.; Sharma, A. K.; Vezzaro, L.; Lützhøft, C.-H. H.; Mikkelsen, P. S. Velocity dependent passive sampling for monitoring of micropollutants in dynamic stormwater discharges. Environ. Sci. Technol. 2013, 47, 12958-12965.

(20) Almeida, M. I. G. S.; Silva, A. M. L.; Coleman, R. A.; Pettigrove, V. J.; Cattrall, R. W.; Kolev, S. D. Development of a passive sampler based on a polymer inclusion membrane for total ammonia monitoring in freshwaters. Anal. Bioanal. Chem. 2016, 408, 32133222.

(21) O’Connor Šraj, L.; Almeida, M. I. G. S.; Bassett, C.; McKelvie, I. D.; Kolev, S. D. Gas-diffusion-based passive sampler for ammonia monitoring in marine waters. Talanta 2018, 181, 52-56.

(22) Voisin, J.; Cournoyer, B.; Mermillod-Blondin, F. Utilisation de billes de verre comme substrats artificiels pour la caractérisation des communautés microbiennes dans les nappes phréatiques : mise au point méthodologique. La Houille Blanche 2015, 52-57.

(23) Vincent-Hubert, F.; Morga, B.; Renault, M. T.; Le Guyader, F. $\mathrm{S}$. Adsorption of norovirus and ostreid herpesvirus type 1 to polymer membranes for the development of passive samplers. J. Appl. Microbiol. 2017, 122, 1039-1047.

(24) de Melo Cassemiro, K. M.; Burlandy, F. M.; Barbosa, M. R. F.; Chen, Q.; Jorba, J.; Hachich, E. M.; Sato, M. I. Z.; Burns, C. C.; da
Silva, E. E. Molecular and Phenotypic Characterization of a Highly Evolved Type 2 Vaccine-Derived Poliovirus Isolated from Seawater in Brazil, 2014. PLOS ONE 2016, 11, e0152251.

(25) World Health Organization World Health Organization, Guidelines for environmental surveillance of poliovirus circulation; World Health Organization: Geneva, 2003.

(26) Ahmed, W.; Bertsch, P. M.; Bivins, A.; Bibby, K.; Farkas, K.; Gathercole, A.; Haramoto, E.; Gyawali, P.; Korajkic, A.; McMinn, B. R.; Mueller, J. F.; Simpson, S. L.; Smith, W. J. M.; Symonds, E. M.; Thomas, K. V.; Verhagen, R.; Kitajima, M. Comparison of virus concentration methods for the RT-qPCR-based recovery of murine hepatitis virus, a surrogate for SARS-CoV-2 from untreated wastewater. Sci. Total Environ. 2020, 739, 139960.

(27) Department of Health and Human Services. Department of Health and Human Services, Victoria. Victorian coronavirus (COVID19) data. 2021, [cited 2021 8th March 2021]; Available from: https://www.dhhs.vic.gov.au/victorian-coronavirus-covid-19-data.

(28) Australian Bureau of Statistics Australian Bureau of Statistics. National, state and territory population. 2020 [cited 2021 8th March, 2021]; Available from: https://www.abs.gov.au/statistics/people/ population/national-state-and-territory-population/jun-2020.

(29) Hill, V. R.; Polaczyk, A. L.; Hahn, D.; Narayanan, J.; Cromeans, T. L.; Roberts, J. M.; Amburgey, J. E. Development of a rapid method for simultaneous recovery of diverse microbes in drinking water by ultrafiltration with sodium polyphosphate and surfactants. Appl. Environ. Microbiol. 2005, 71, 6878-6884.

(30) Forootan, A.; Sjöback, R.; Björkman, J.; Sjögreen, B.; Linz, L.; Kubista, M. Methods to determine limit of detection and limit of quantification in quantitative real-time PCR (qPCR). Biomol. Detect. Quantif. 2017, 12, 1-6.

(31) Klymus, K. E.; Merkes, C. M.; Allison, M. J.; Goldberg, C. S.; Helbing, C. C.; Hunter, M. E.; Jackson, C. A.; Lance, R. F.; Mangan, A. M.; Monroe, E. M.; Piaggio, A. J.; Stokdyk, J. P.; Wilson, C. C.; Richter, C. A. Reporting the limits of detection and quantification for environmental DNA assays. Environ. DNA 2020, 2, 271-282.

(32) Kralik, P.; Ricchi, M. A Basic Guide to Real Time PCR in Microbial Diagnostics: Definitions, Parameters, and Everything. Front. Microbiol. 2017, 8, 108.

(33) Grant, S. B.; List, E. J.; Lidstrom, M. E. Kinetic analysis of virus adsorption and inactivation in batch experiments. Water Resour. Res. 1993, 29, 2067-2085. 


\section{University Library}

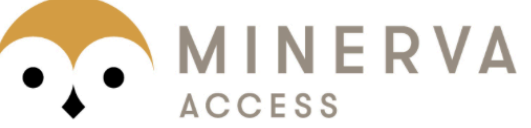

A gateway to Melbourne's research publications

Minerva Access is the Institutional Repository of The University of Melbourne

\section{Author/s:}

Schang, C;Crosbie, ND;Nolan, M;Poon, R;Wang, M;Jex, A;John, N;Baker, L;Scales, P;Schmidt, J;Thorley, BR;Hill, K;Zamyadi, A;Tseng, C-W;Henry, R;Kolotelo, P;Langeveld, J;Schilperoort, R;Shi, B;Einsiedel, S;Thomas, M;Black, J;Wilson, S;McCarthy, DT

Title:

Passive Sampling of SARS-CoV-2 for Wastewater Surveillance

Date:

2021-08-03

\section{Citation:}

Schang, C., Crosbie, N. D., Nolan, M., Poon, R., Wang, M., Jex, A., John, N., Baker, L., Scales, P., Schmidt, J., Thorley, B. R., Hill, K., Zamyadi, A., Tseng, C. -W., Henry, R., Kolotelo, P., Langeveld, J., Schilperoort, R., Shi, B. ,... McCarthy, D. T. (2021). Passive Sampling of SARS-CoV-2 for Wastewater Surveillance. Environmental Science and Technology (Washington), 55 (15), pp.10432-10441. https://doi.org/10.1021/ acs.est.1c01530.

Persistent Link:

http://hdl.handle.net/11343/282467

License:

CC BY-NC-ND 